\title{
Challenges impeding integration of oral health into primary health care
}

\author{
Zahra Ghorbani 1,2, Mina Pakkhesal ${ }^{2}$, Shahnam Arshi ${ }^{3}$, Mohammad J. Eghbal ${ }^{4}$, Marzieh Deghatipour ${ }^{2}$, Marc Tennant ${ }^{5}$ and \\ H. Malekafzali Ardakani ${ }^{6}$
}

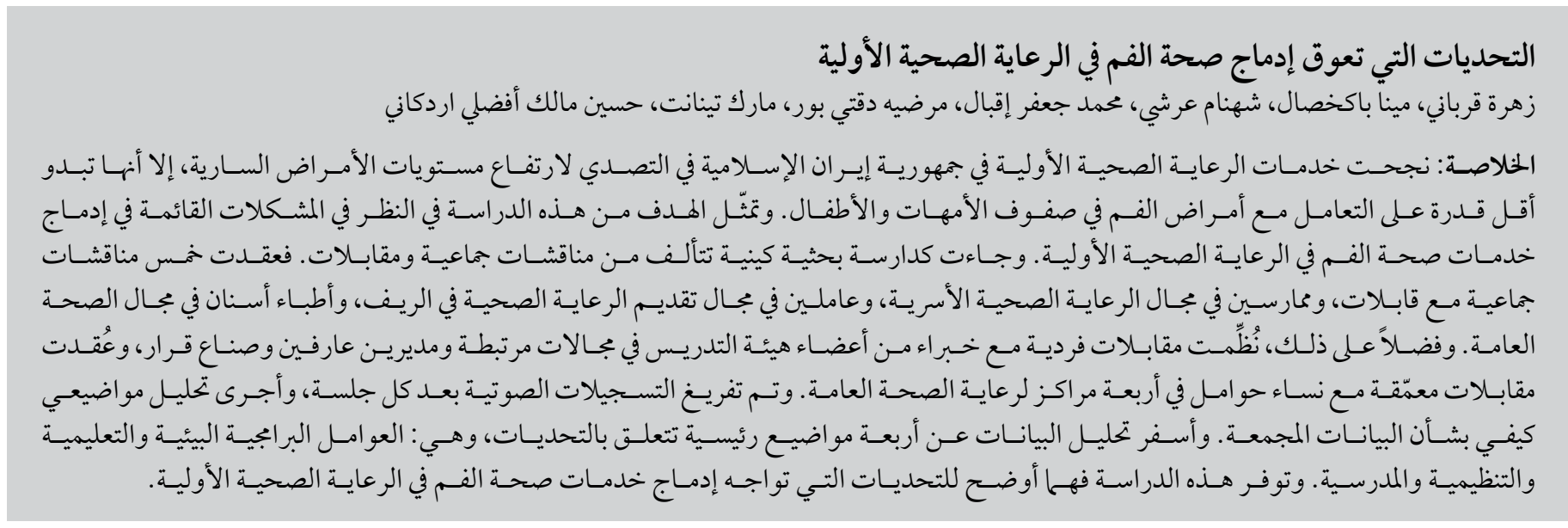

ABSTRACT The primary healthcare (PHC) services in the Islamic Republic of Iran have succeeded in addressing high levels of communicable diseases; however, they seem less able to deal with maternal and paediatric oral diseases. The aim of this study was to examine problems in integrating oral health services into PHC. This was a qualitative research study comprising focus group discussions and interviews. Five focus-group discussions were held with midwives, family healthcare practitioners, rural PHC workers, duty-service dentists, and public health dentists. Also, individual interviews were organized with experts of faculty members in related fields, informant managers and policy makers, and in-depth interviews were done with pregnant women in four PHC centres. Audiotapes were transcribed following each session, and then a qualitative thematic analysis was carried out on gathered data. Data analysis resulted in 4 main themes relating to the challenges: environmental, educational, organizational and school-based programme factors. This study provides a clearer understanding of the challenges of integrating oral health services into PHC.

\section{Les obstacles à l'intégration de la santé bucco-dentaire aux soins de santé primaires}

RÉSUMÉ Les services de soins de santé primaires en République islamique d'Iran sont parvenus avec succès à traiter le nombre élevé de cas de maladies transmissibles. Néanmoins, il semblerait qu'ils soient moins performants dans la prise en charge des maladies bucco-dentaires de la mère et de l'enfant. La présente étude avait pour objectif d'examiner les obstacles à l'intégration de la santé bucco-dentaire aux services de soins de santé primaires. Il s'agissait d'une étude de recherche qualitative comprenant des groupes de discussion et des entretiens. Cinq groupes de discussion ont été tenus. Il réunissaient des sages-femmes, des médecins de famille, des agents de soins de santé primaires en milieu rural, des dentistes suppléants, et des dentistes en santé publique. Des entretiens individuels ont également été organisés avec des experts membres du corps enseignant des domaines concernés, des gestionnaires en charge de la planification et de la coordination et des responsables politiques. D'autre part, des entretiens approfondis ont été menés auprès de femmes enceintes dans quatre établissements de soins de santé primaires. Des cassettes audio ont été retranscrites à la suite de chaque session, et une analyse thématique qualitative a été menée sur les données recueillies. L'analyse des données a fait ressortir quatre types de problèmes principaux liés à des facteurs d'ordre environnemental et organisationnel, et concernant la formation des praticiens et les programmes scolaires. La présente étude permet une compréhension plus détaillée des obstacles à l'intégration des services de santé bucco-dentaires aux soins de santé primaires.

${ }^{I}$ Preventive Dentistry Research Center, Research Institute of Dental Sciences, Dental School, Shahid Beheshti University of Medical Sciences, Tehran, Islamic Republic of Iran. ${ }^{2}$ Community Oral Health Department, School of Dentistry, Shahid Beheshti University of Medical Sciences, Tehran, Islamic Republic of Iran (Correspondence to: M. Pakkhesal: m_pakkhesal@yahoo.com). ${ }^{3}$ Department of Public Health Sciences, Shahid Beheshti University of Medical Sciences, Tehran, Islamic Republic of Iran. ${ }^{4}$ Dental Research Center, Iranian Center for Endodontic Research, Dental School, Shahid Beheshti University of Medical Sciences, Tehran, Islamic Republic of Iran. ${ }^{5}$ School of Anatomy, Physiology and Human Biology, University of Western Australia, Perth, WA, Australia. ${ }^{6}$ Epidemiology and Biostatistics Department, School of Public Health, Tehran University of Medical Sciences, Tehran, Islamic Republic of Iran. Received: 05/10/16; accepted: 23/01/17 


\section{Introduction}

Oral health is a critical component of overall health and well-being; yet, oral disease remains a silent epidemic (1). Many children in developed and developing countries, especially those from deprived areas, are affected by dental caries and suffer from pain and infection associated with their teeth and gums (2). The prevalence of caries increases with age, especially in high-risk children with limited access to oral health services (3). Furthermore, dental caries in deciduous dentition predicts later caries experience in adulthood (4). So, it seems that prevention and early initiation of dental care, especially provided in a primary healthcare (PHC) setting, can lead to improved oral health outcomes and are both cost saving and effective (5-7).

Pregnancy represents a unique and sensitive period of maternal oral health, and due to changes in hormonal levels, pregnant women are more susceptible to oral diseases. Possible adverse pregnancy outcomes, including low birth weight, preterm birth, pre-eclampsia and miscarriages have been reported as consequences of oral diseases. It is also widely accepted that poor maternal oral health is a predictor of early childhood caries, and education of pregnant women can effectively prevent early childhood caries (1).

A majority of babies, young children and pregnant women do not undertake regular dental visits; instead, they frequently visit $\mathrm{PHC}$ providers for routine check-ups. These check-ups provide an opportunity to integrate oral health promotion into the practices of nondental staff in public health centres. Sharing the responsibility for child oral health care with PHC creates opportunities for interprofessional efforts to target this at-risk population $(8,9)$.

Structured PHC in the Islamic Republic of Iran was established in the 1970s, and integration of oral health care into the nationwide PHC network followed in 1997 (10). Oral health was integrated into the monitoring programmes for maternal and child care through which the responsibility for oral health education, primary screening and referral to the dentist was assigned to the PHC workers, including midwives, family health physicians and rural healthcare workers. About $60 \%$ of PHC centres have an oral healthcare unit with a dentist who is in charge of basic services, such as restoration, scaling and extraction, mainly for target groups consisting of children aged $<12$ years, pregnant women and nursing mothers (9). The PHC services in the Islamic Republic of Iran have clearly succeeded in addressing high levels of communicable diseases and maternal and infant mortality, but have been less effective in dealing with maternal and paediatric oral diseases. The aim of this study was to explore the considerable challenges of integrating oral health promotion into PHC in Iran.

\section{Methods}

\section{Study design}

The present study used a qualitative research design consisting of 3 sources of data: focus group discussions, individual interviews with experts, and semistructured interviews with pregnant women.

\section{Focus group discussions and interviews}

Five focus groups were held with midwives, family healthcare practitioners, rural PHC workers, duty-service dentists and public health dentists. Each focus group consisted of 10 participants and lasted 2-2.5 hours. Purposive sampling was used to select the members of each focus group, since researchers needed to consider who could best address the research questions. A moderator asked the participants to think about the various challenges with which they dealt in the integration of oral health care into PHC services. The focus groups provided detailed explanations and examples of positive and negative experiences and views regarding oral healthcare integration into PHC.

Semistructured interviews were conducted with a convenience sample of 27 pregnant women seeking regular maternal care in 4 selected PHC centres. A purposive sampling method was initially used for selection of 4 PHC centres with high levels of provision of maternal and paediatric services located in 2 deprived regions of Tehran Province. Women were eligible for inclusion in the study if they were aged $\geq 20$ years; were in 2nd or 3rd trimester of pregnancy; and were willing to participate in the interview. They were asked whether they received any examination, service or education regarding oral health in their last maternal visit, and what oral health care did they expect to receive via PHC. The average length of each interview was 20 minutes. The interviews were transcribed individually and the sampling continued until data saturation was reached.

Semistructured and individual interviews were also conducted with 10 experts lasting for 45 minutes to 2 hours. The sample included experts from 3 groups consisting of faculty members in related fields, informed managers and policy makers in the Iranian health system using purposive sampling. The participants were asked whether they were aware of the history of the integration of oral health into $\mathrm{PHC}$, and if they thought the programme was successful, and if not, what were the causes.

The interview guide for each group was developed from our literature review and after discussions among the team members; these were then piloted with an expert and a pregnant woman. Some questions were reworded to make them clearer and some subquestions were added to the interview guide as a result of the piloting. Three authors (MP, ZG and MD) conducted the 
interviews and focus group discussions between July 2015 and February 2016.

\section{Data analysis}

Thematic analysis was used to analyse and organize the collected data. First, 2 researchers (MP and MD) read and reread the text transcription of each focus group discussion and interview, independently, to identify units of meaning related to the subject. Then, all of the units of meaning were categorized into initial themes. After matching the initial themes through informal discussion, the research team categorized the initial themes into overarching themes that were labelled as an inductive or bottomup approach. The proposed labels for the main themes were discussed and achieved through consensus. The principal investigator $(\mathrm{ZG})$ resolved any disagreement between the research team by discussion and made the final decision.

The robustness of the data should be acknowledged because the research team attempted to maximize the validity of the study in 3 main ways: 1) they attempted to take control of their own perspectives and expectations; 2) the transcripts were independently analysed by 2 members of the research team, and any disagreements were discussed by the team; and 3) to cover all the viewpoints about the topic, we tried to cover all the potential stakeholders.

We attempted to contact all participants who had been involved in planning and/or provision of oral health services delivered in PHC centres. The different stakeholders were selected to provide a wide range of views in the oral health services that are delivered in PHC centres, based on their perspectives. It also allowed us to compare and recognize the different perspectives of different stakeholders in this regard.

\section{Ethical issues}

This study was approved by the 27 th Research Ethics Committee of the Research Institute of Dental Sciences,
Shahid Beheshti University of Medical Sciences (number: IR.SBMU.RIDS. REC.1395.188). The participants were clarified about the aims of the study and verbal consent was obtained for participation. It was confirmed that participation in the study was completely voluntary, respecting the confidentiality of the data.

\section{Results}

\section{Study participants}

The characteristics of the 5 focus group members $(\mathrm{n}=50)$, and experts $(\mathrm{n}=10)$ participating in the study are shown in Table 1 . The educational background of the experts was dental sciences ( $\mathrm{n}$ $=6)$, medical $/$ health sciences $(n=3)$ and nursing care $(\mathrm{n}=1)$. Mean age (standard deviation) of the 27 pregnant women participating in the interviews was 28.6 (5.8) years, ranging from 20 to 40 years. Most of the pregnant women had finished high school (41\%) and were in the 2 nd trimester (63\%), experiencing their $2 \mathrm{nd}$ pregnancy (52\%). Analysis of the data from the focus groups and interviews gave rise to 21 subthemes; later classified into 4 main themes in line with the methods (Table 2) related to environmental, educational, organizational and schoolbased programme factors.

\section{Educational factors}

Many PHC providers believed that providing preventive oral health services was not their responsibility. Specifically, midwives thought that they were not sufficiently qualified to assess oral health nor to ask specific questions about it. However, most of them expressed interest and willingness to complete appropriate training programmes.

Some dentists stated that they feared the legal consequences of potential complaints about their practice, and therefore avoided performing procedures on pregnant women. They expressed that they were not provided with clear protocols for managing some dental problems during pregnancy, and most of them were not covered by responsibility insurance. The pregnant women's insufficient knowledge and demand for oral health care were other challenges in this study. The pregnant women felt that poor oral health was a normal outcome of pregnancy and there was no need to consult a dentist.

\section{Environmental factors}

According to focus group participants, nowadays, people go where they obtain good services. They usually go to the clinics that have advanced technology instead of to dispensaries where there are limited equipment and facilities. Some focus group participants also reported that the physical infrastructure and available equipment, such as modern dental chairs, instruments and materials, were not suitable to provide oral health education and dental screening.

\section{Organizational factors}

PHC providers consistently talked about time limitation as a key barrier to providing oral health education and dental examination. They were involved in the provision of vaccination and child and maternal care, leading to crowded clinic waiting areas. One midwife complained about insufficient human resources and high workload. Another reported that some mothers failed to arrive on time for appointments, for various reasons, especially early in the morning, therefore, there was often overcrowding in the middle of the day. She reported that because of these time and human resource constraints, they were unable to counsel mothers regarding oral health.

Many of the focus group participants noted that using paper recordkeeping instead of integrated electronic records wasted a lot of time in the majority of PHC centres. The existing salary-based payment system for all PHC providers did not provide incentives to improve their performance. 


\begin{tabular}{|c|c|c|c|c|c|c|}
\hline \multirow[t]{2}{*}{ Variables } & \multicolumn{5}{|c|}{ Focus groups } & \multirow{2}{*}{$\begin{array}{c}\text { Interviews } \\
\text { Experts }\end{array}$} \\
\hline & $\begin{array}{c}\text { Rural primary } \\
\text { healthcare } \\
\text { workers }\end{array}$ & Midwives & $\begin{array}{c}\text { Family } \\
\text { healthcare } \\
\text { practitioners }\end{array}$ & $\begin{array}{l}\text { Duty-service } \\
\text { dentists }\end{array}$ & $\begin{array}{l}\text { Public health } \\
\text { dentists }\end{array}$ & \\
\hline \multicolumn{7}{|l|}{ Sex } \\
\hline Female & 6 & 10 & 10 & 8 & 7 & 3 \\
\hline Male & 4 & 0 & 0 & 2 & 3 & 7 \\
\hline \multicolumn{7}{|l|}{ Age (yr) } \\
\hline $20-30$ & 2 & 3 & 2 & 10 & 0 & 0 \\
\hline $31-40$ & 5 & 5 & 6 & 0 & 2 & 0 \\
\hline$\geq 41$ & 3 & 2 & 2 & 0 & 8 & 10 \\
\hline \multicolumn{7}{|c|}{ Length of practice (yr) } \\
\hline$<10$ & 4 & 4 & 3 & 10 & 1 & 1 \\
\hline $10-20$ & 3 & 3 & 4 & 0 & 2 & 4 \\
\hline $20-30$ & 3 & 3 & 3 & 0 & 7 & 5 \\
\hline Total & 10 & 10 & 10 & 10 & 10 & 10 \\
\hline
\end{tabular}

Inadequate advocacy was another challenge noted by some experts, and that powerful community individuals (such as religious leaders and local government managers) were not involved in developing and disseminating health programmes.

\section{School-based programme factors}

Most focus group participants and experts reported inadequate support for school-based oral health programmes. They also believed that parents and school staff were not involved in developing school-based oral health programmes and therefore not committed to achieving the programme goals. Some focus group participants were dissatisfied with inadequate physical space in the schools for implementation of oral health programmes.

\section{Discussion}

This study used a qualitative research design to understand the challenges that impede integration of oral health programmes into PHC. Qualitative methods seem to be an appropriate design for exploring complex phenomena about which little is known $(11,12)$.
This study revealed 4 main themes relating to the challenges of integration of oral health into PHC: educational, environmental, organizational and school-based factors.

With regard to educational factors and in agreement with our findings, many studies have shown that insufficient knowledge and inappropriate perception among pregnant women about oral health are common causes of the decrease in dental care demand during pregnancy (13-15). Also, the majority of pregnant women believe that dental treatment during pregnancy might have a negative effect on pregnancy outcome (16). Many pregnant women still believe in the folk myth of "a tooth for a child", which suggests an association between childbearing and loss of teeth, and they perceive that gingival bleeding does not indicate inflammatory disease that requires professional help (17). Mothers are unaware that vertical transmission of cariogenic microbes contributes to the development of dental caries in children $(17,18)$. They are also unaware about the importance of cleaning deciduous teeth, proper feeding practices, and the important role of early-onset regular dental visits for their children (19). Furthermore, the insufficient knowledge of PHC workers about oral health has been highlighted in studies from other countries (20-24). As a result, oral health is often neglected by maternal-care providers during prenatal care, and is only discussed when initiated by pregnant women (21). The need for community-based education of dental students is also noted in the literature (25). With regard to the problem of unclear guidelines for dentists about treatment of pregnant women, evidence-based guidelines have been developed with a focus on tracking oral health services, screening, and triaging prenatal patients for oral health risks to the mother, fetus and baby (26). Such guidelines need to be reviewed and customized according to the local and structural situations of each country.

On the topic of environmental factors, the need for increasing financial investment and human resources to develop primary oral health care has been mentioned as an integral part of PHC (27). The time limitations for $\mathrm{PHC}$ providers to provide oral health education and screening have also been identified as a challenging barrier $(8,24)$.

With regard to organizational factors, insufficient interprofessional collaboration has been considered 


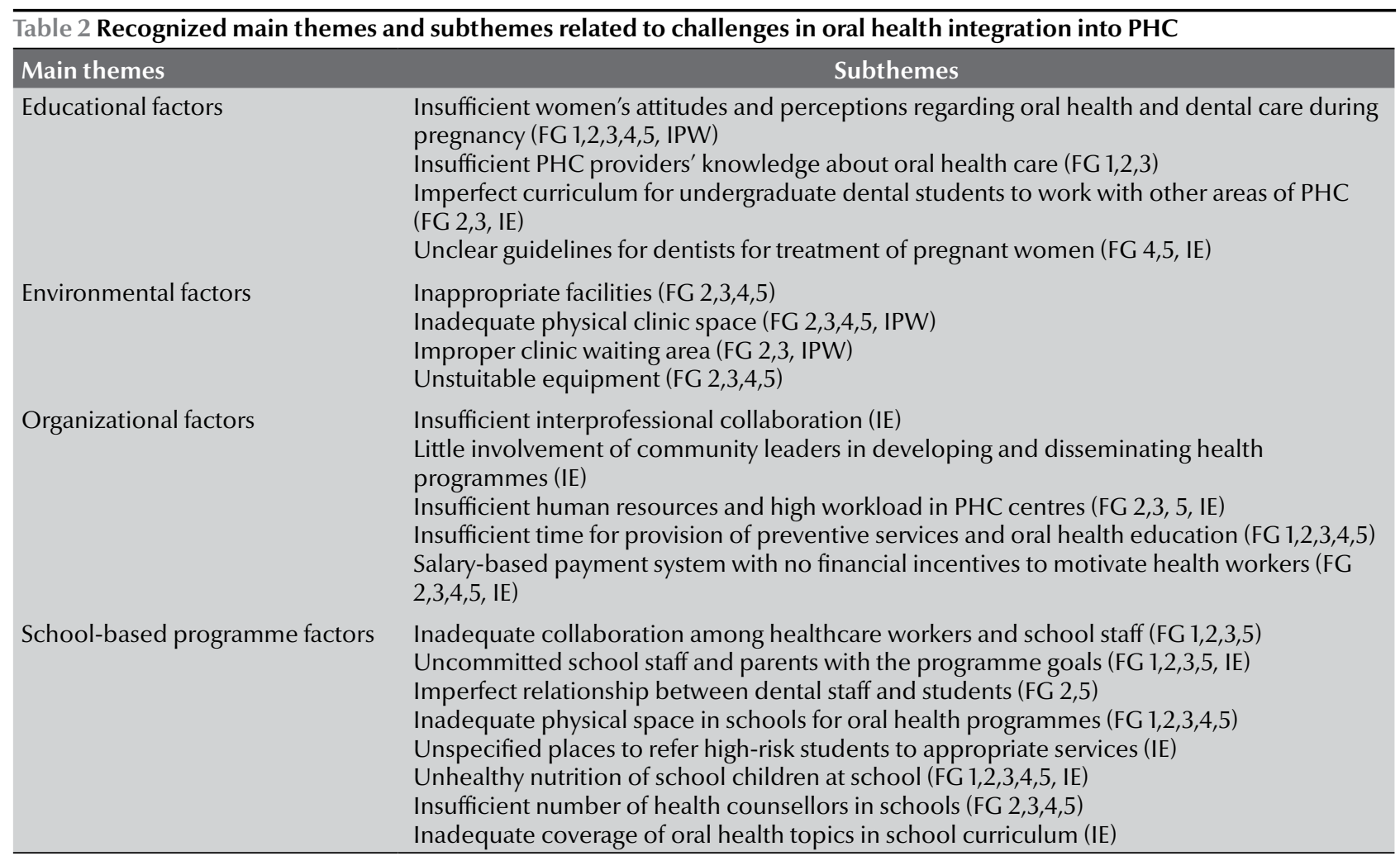

$F G 1=$ focus group with rural primary healthcare workers; $F G 2=$ focus groups with midwives; $F G 3=$ focus group with family healthcare practitioners; $F G 4=$ focus group with duty-service dentists; FG $5=$ focus group with public health dentists; IE = interview with experts; IPW= interview with pregnant women.

elsewhere (19) and has led to generation of a model to educate dental and medical practitioners about these factors. The model involves a system of referral for comprehensive clinical care of pregnant women, and an educational guide for women about their oral health and that of their children. Such programmes can help meet interprofessional accreditation standards and encourage implementation of practice guidelines (28).

Similar to our findings, a lack of provider capacity, training and experience for operating in the context of cross-disciplinary or integrated settings is another challenge considered in the literature $(22,23)$. It is also suggested that integration of the PHC approach into the dental curriculum is crucial for training a competent workforce (29). Given this situation, there is a need to provide the current and future PHC and dental workforce with the skills needed to practice integrated oral health services $(23,30)$. The limitations of time and human resources for PHC providers are another organizational challenge that has been addressed to some extent by using lay health workers as the main facilitators of oral health programmes in some contexts (8).

In relation to school-based factors, the Ottawa Charter for Health Promotion notes that schools can provide a supportive environment for promoting child health. The survey of Jurgensen and Petersen has demonstrated the important role of oral health education in promoting oral health among school-aged children (31). The main factors identified as barriers for successful implementation of school-based oral health programmes were: financial constraints; inadequate capacity and availability of human resources; lack of collaboration at local level; inadequate policy framework; lack of high-level leadership and governance; poor attitude, support and awareness among school health team, parents and the local community leaders; and failure to provide quality services (31).

This study tried to gather the views of all potential stakeholders involved in planning, providing and receiving integrated oral health services. Despite the small number of participants in each group, the sample size was appropriate considering the qualitative methodological approach, which emphasized the purposeful selection of informationrich cases that provided in-depth data. We selected participants according to their experience of oral health care provided as PHC services and their ability to express their perspectives. However, the most recent improvements in management and planning in the Iranian Ministry of Health have addressed to some extent some of the barriers found in this study. For instance, electronic health records have been recently used in PHC centres, facilitating time management among workers. Also, the renovation of dental offices in PHC settings has been emphasized in the past 
year, which could potentially improve dental care services (32). We should also acknowledge that all the findings might not be generalized to other countries because of the distinct culture and structure of the healthcare system in the Islamic Republic of Iran. However, some of the findings will be helpful for other countries to consider developing their own integrated oral healthcare systems.

Our findings will serve as an initial step towards establishing evidencebased interventions and identifying potential gaps to guide future efforts. The next step will be identification and prioritization of solutions related to the barriers to integration of oral health care into the PHC system. The experiences from other countries can be used in this regard. For instance, the Brazilian unified PHC system is suggested to benefit from a mixed approach, by focusing on social factors (upstream) and simultaneously preventing modifiable risk factors at the individual level (downstream), to tackle the serious obstacles to achieving universal access to integrated oral health services (33).

In conclusion, since administrative and clinical leadership support can be critical to the success of integrative approaches, this study provides a better understanding of the challenges around integrating oral health services into PHC, including environmental, educational, organizational and school-based programme factors.

\section{Acknowledgements}

This study was supported by Preventive Dentistry Research Center, Research
Institute of Dental Sciences, Dental School, Shahid Beheshti University of Medical Sciences, Tehran, Islamic Republic of Iran. We would like to thank the Vice Chancellor in Health Affairs of Shahid Beheshti University of Medical Sciences, Dr. Bastani, Dr. Taheri, Dr. Ghanbari, Dr. Ehdaeivand, Dr. Shahzadeh Fazeli and Dr. Khoshnevisan who were involved at different stages of this research. Finally, we express our gratitude to the people who participated in focus group discussions and individual interviews with midwives, family healthcare practitioners, rural PHC workers, dentists, experts, and pregnant women for sharing their experiences and views regarding oral healthcare integration into PHC.

\section{Funding: None.}

Competing interests: None declared.

\section{References}

1. Vamos CA, Thompson EL, Avendano M, Daley EM, Quinonez $\mathrm{RB}$, Boggess K. Oral health promotion interventions during pregnancy: a systematic review. Community Dent Oral Epidemiol. 2015 Oct;43(5):385-96. PMID:25959402

2. De Grauwe A, Aps J, Martens L. Early childhood caries (ECC): what's in a name? Eur J Paediatr Dent. 2004 Jun;5(2):62-70. PMID:15198622

3. Vargas CM, Monajemy N, Khurana P, Tinanoff N. Oral health status of preschool children attending Head Start in Maryland. Pediatr Dent. 2000 May-Jun;24(3):257-63. PMID:12064502

4. Jatrana S, Crampton P. Primary health care in New Zealand: who has access? Health Policy. 2009 Nov;93(1):1-10. PMID:19535163

5. Jokela J, Pienihäkkinen K. Economic evaluation of a risk-based caries prevention program in preschool children. Acta Odontol Scand. 2003 Apr;61(2):110-4. PMID:12790509

6. Savage MF, Lee JY, Kotch JB, Vann WF Jr. Early preventive dental visits: Effects on subsequent utilization and costs. Pediatrics. 2004 Oct;114(4):e418-23. PMID:15466066

7. Crall JJ. Development and integration of oral health services for preschool-age children. Pediatr Dent. 2005 Jul-Aug;27(4):32330. PMID:16317973

8. Vichayanrat T, Steckler A, Tanasugarn C. Barriers and facilitating factors among lay health workers and primary care providers to promote children's oral health in Chon Buri Province, Thailand. Southeast Asian J Trop Med Public Health. 2013 Mar;44(2):332-43. PMID:23691643

9. Rabiei S, Mohebbi SZ, Yazdani R, Virtanen JI. Primary care nurses' awareness of and willingness to perform children's oral health care. BMC Oral Health. 2014 Mar 26;14:26. PMID:24670004
10. Moghadam MN, Sadeghi V, Parva S. Weaknesses and challenges of primary healthcare system in Iran: a review. Int J Health Plann Manage. 2012 Apr-Jun;27(2):21-31. PMID:22009801

11. Bedos C, Levine A, Brodeur JM. How people on social assistance perceive, experience, and improve oral health. J Dent Res. 2009 Jul;88(7):653-7. PMID:19641153

12. Loignon C, Allison P, Landry A, Brodeur JM, Bedos C. Providing humanistic care: dentists' experiences in deprived areas. J Dent Res. 2010 Sep;89(9):991-5. PMID:20525962

13. Al Habashneh R, Guthmiller JM, Levy S, Johnson GK, Squier C, Dawson DV et al. Factors related to utilization of dental services during pregnancy. J Clin Periodontol. 2005 Jul;32(7):815-21. PMID:15966891

14. Hullah E, Turok Y, Nauta M, Yoong W. Self-reported oral hygiene habits, dental attendance and attitudes to dentistry during pregnancy in a sample of immigrant women in North London. Arch Gynecol Obstet. 2008 May;277(5):405-9. PMID:17940783

15. Bamanikar S, Kee LK. Knowledge, attitude and practice of oral and dental healthcare in pregnant women. Oman Med J. 2013 Jul;28(4):288-91. PMID:23904926

16. Dinas K, Achyropoulos V, Hatzipantelis E, Mavromatidis G, Zepiridis L, Theodoridis T et al. Pregnancy and oral health: utilisation of dental services during pregnancy in northern Greece. Acta Obstet Gynecol Scand. 2007;86(8):938-44. PMID:17653878

17. Keirse MJ, Plutzer K. Women's attitudes to and perceptions of oral health and dental care during pregnancy. J Perinat Med. 2010;38(1):3-8. PMID:20047523

18. Mohebbi SZ, Virtanen JI, Vahid-Golpayegani M, Vehkalahti MM. A cluster randomised trial of effectiveness of educational intervention in primary health care on early childhood caries. Caries Res. 2009;43(2):110-8. PMID:19321988 
19. Ramos-Gomez FJ. A model for community-based pediatric oral heath: implementation of an infant oral care program. Int J Dent. 2014;2014:156821. PMID:24587803

20. Wooten KT, Lee J, Jared H, Boggess K, Wilder RS. Nurse practitioners' and certified nurse midwives' knowledge, opinions and practice behaviors regarding periodontal disease and adverse pregnancy outcomes. J Dent Hyg. 2011 Spring;85(2):122-31. PMID:21619740

21. George A, Shamim S, Johnson M, Dahlen H, Ajwani S, Bhole S, et al. How do dental and prenatal care practitioners perceive dental care during pregnancy? Current evidence and implications. Birth. 2012 Sep;39(3):238-47. PMID:23281906

22. Rabiei S, Mohebbi SZ, Patja K, Virtanen JI. Physicians' knowledge of and adherence to improving oral health. BMC Public Health. 2012 Oct 9;12:855. PMID:23046660

23. Sandhya MP, Shanthi M, Fareed N, Sudhir KM, Kumar RK. Effectiveness of oral health education among primary health care workers at the primary health center in Nellore district, Andhra Pradesh. J Indian Assoc Public Health Dent. 2014;12(2):74-9.

24. Rozier G, Sutton BK, Bawden JW, Haupt K, Slade GD, King RS. Prevention of early childhood caries in North Carolina medical practices: implications for research and practice. J Dent Educ. 2003 Aug;67(8):876-85. PMID:12959161

25. Mofidi M, Strauss R, Pitner LL, Sandler ES. Dental students reflections on their community-based experiences: the use of critical incidents. J Dent Educ. 2003 May;67(5):515-23. PMID:12809186
26. Stevens J. Lida H, Ingersoll G. Implementing an oral health program in a group prenatal practice. J Obstet Gynecol Neonatal Nurs. 2007 Nov-Dec;36(6):581-91. PMID:17973702

27. Honkala E. Primary oral health care. Med Princ Pract. 2014;23(Suppl 1):17-23. PMID:24503932

28. Jackson JT, Quninonez RB, Kerns AK, Boggess K, Chuang A, Eidson RS, et al. Implementing a prenatal oral health program through interprofessional collaboration. J Dent Educ. 2015 Mar;79(3):241-8. PMID:25729017

29. Mumghamba EG. Integrating a primary oral health care approach in the dental curriculum: a Tanzanian experience. Med Princ Pract. 2014;23(Suppl 1):69-77. PMID:24246734

30. Norwood CW, Maxey HL, Randolph C, Gano L, Kochhar K. Administrative challenges to the integration of oral health with primary care: a SWOT analysis of health care executives at federally qualified health centers. J Ambul Care Manage. 2016 May 23; [Epub ahead of print] PMID:27218701

31. Jürgensen N, Petersen PE. Promoting oral health of children through schools - results from a WHO global survey 2012. Community Dent Health. 2013 Dec;30(4):204-18. PMID:24575523

32. Moradi-Lakeh M, Vossogh-Moghaddam A. Health sector evolution plan in Iran; equity and sustainability concerns. Int J Health Policy Manag. 2015 Aug 31;4:637-40. PMID:26673172

33. Nascimento AC, Moysés ST, Werneck RI, Moysés SJ. Oral health in the context of primary care in Brazil. Int Dent J. 2013 Oct;63(5):237-43. PMID:24074017 